\title{
Hypoxia-inducible factors as molecular targets for liver diseases
}

\author{
${\text { Cynthia } \mathrm{Ju}^{1} \cdot \text { Sean P. Colgan }}^{2} \cdot$ Holger K. Eltzschig ${ }^{3}$
}

Received: 3 February 2016/Revised: 4 March 2016 / Accepted: 8 March 2016/Published online: 20 April 2016

(C) The Author(s) 2016. This article is published with open access at Springerlink.com

\begin{abstract}
Liver disease is a growing global health problem, as deaths from end-stage liver cirrhosis and cancer are rising across the world. At present, pharmacologic approaches to effectively treat or prevent liver disease are extremely limited. Hypoxia-inducible factor (HIF) is a transcription factor that regulates diverse signaling pathways enabling adaptive cellular responses to perturbations of the tissue microenvironment. HIF activation through hypoxia-dependent and hypoxiaindependent signals have been reported in liver disease of diverse etiologies, from ischemia-reperfusion-induced acute liver injury to chronic liver diseases caused by viral infection, excessive alcohol consumption, or metabolic disorders. This review summarizes the evidence for HIF stabilization in liver disease, discusses the mechanistic involvement of HIFs in disease development, and explores the potential of pharmacological HIF modifiers in the treatment of liver disease.
\end{abstract}

Keywords HIF $1 \alpha \cdot \operatorname{HIF} 2 \alpha \cdot \mathrm{HIF} 1 \alpha \cdot$ Ischemia-reperfusion liver injury · Fatty liver · Viral hepatitis · Alcoholic liver disease $\cdot$ Hepatocellular carcinoma

Cynthia Ju

cynthia.ju@ucdenver.edu

1 Department of Pharmaceutical Sciences, Skaggs School of Pharmacy, University of Colorado, Auroa, Colorado 800045, USA

2 Department of Medicine and Mucosal Inflammation Program, School of Medicine, University of Colorado, Auroa, Colorado 800045, USA

3 Department of Anesthesiology and Organ Protection Program, School of Medicine, University of Colorado, Auroa, Colorado 800045, USA

\section{Introduction}

Acute and chronic liver diseases are a significant global public health issue. Acute liver injury due to adverse drug reactions accounts for more than half of the cases of acute liver failure and $15 \%$ of the patients undergoing liver transplantation. Ischemia-reperfusion (IR) is another major cause of acute liver injury, which represents a key challenge in liver transplantation and significantly contributes to postoperative morbidity and mortality. Chronic liver diseases caused by viral infection, alcohol abuse, or obesity-associated metabolic disorder can develop into end-stage liver cirrhosis and liver cancer. It is estimated that in 2013 alone, there were 792,000 new cases of liver cancer and 818,000 deaths globally, with $86 \%$ occurring in developing countries and $14 \%$ occurring in developed countries [1].

Hypoxia-inducible factor (HIF) is a transcription factor regulating a wide range of genes involved in cellular responses to hypoxia and other tissue environmental cues. HIF is a heterodimeric complex consisting of a constitutively expressed $\beta$ subunit and an oxygen-sensitive $\alpha$-subunit. To date, three isoforms of HIF- $\alpha$ subunit have been described, in which HIF $1 \alpha$ and HIF $2 \alpha$ are the best characterized. The $\alpha$ subunit is rapidly degraded under normoxic conditions and stabilized during hypoxia. The critical step in $\alpha$-subunit degradation is the hydroxylation of proline residues by prolyl hydroxylase domain enzymes (PHD1-3), allowing recognition of the $\alpha$-subunit by the von Hippel-Lindau (VHL) E3 ubiquitin ligase complex and subsequent proteasomal degradation [2, 3]. During hypoxia, PHD activity is limited by oxygen availability, leading to the stabilization of HIF- $\alpha$ subunit and its nuclear translocation. The $\alpha$ and $\beta$ subunits heterodimerize and form a complex with CREB-binding protein (CBP)/p300, thereby exerting their transcriptional activity. A second hypoxic switch operates in the carboxy terminal transactivation domain of HIF- $\alpha$, where 
hypoxia blocks the hydroxylation of Asn803, thereby facilitating the recruitment of $\mathrm{CBP} / \mathrm{p} 300$ [4].

Increased expression of HIF- $1 \alpha$ and HIF- $2 \alpha$ has been reported in many liver diseases, including nonalcoholic fatty liver disease (NAFLD), alcoholic liver disease (ALD), IR-induced liver injury, and hepatocellular carcinoma (HCC) [5-10]. A common feature of these liver diseases is tissue hypoxia due to an imbalance of metabolic demand and supply [11-14]. Oxygen consumption by hepatocytes and infiltrating inflammatory leukocytes is dramatically increased. For example, infiltrating neutrophils consume copious amounts of oxygen during oxidative burst. [15] In the meantime, oxygen supply is reduced due to vascular dysfunction, thrombosis, or fibrosis. Aside from hypoxia, other conditions associated with liver disease can also stabilize HIFs. For example, hepatic endotoxin levels are increased in NAFLD and ALD, and lipopolysaccharide (LPS) has been reported to stabilize HIF [16-18]. LPS-induced HIF activation is dependent on toll-like receptor (TLR)-4 and mediated through NF-KB and MAPK pathways [16, 17]. During inflammation, a TCA cycle intermediate, succinate is increased, and it functions as a HIF activator [19]. Reactive oxygen species (ROS) has also been shown to stabilize HIFs [20], and increased production of ROS is a common phenomenon in liver pathological conditions. Furthermore, evidence suggests that hepatitis $\mathrm{B}$ and $\mathrm{C}$ viruses directly stabilize HIFs under normoxic conditions (Fig. 1).

HIFs transcriptionally regulate a wide range of genes involved in cell proliferation (e.g., transforming growth factor (Tgf $\alpha$ ) and insulin-like growth factor (Igf-2)), energy metabolism (e.g., pyruvate dehydrogenase kinase (Pdk1) and glucose transporter (Glut-1)), migration (e.g., zinc finger protein SNAI1 (Snail), twist family BHLH transcription factor (Twist1) and matrix metalloproteinases (MMPs)), and angiogenesis (e.g., vascular endothelial growth factor (Vegf) and platelet-derived growth factor (Pdgf-b)). A common response to both acute and chronic tissue injury is inflammation. HIF plays an important role in regulating innate and adaptive immune cells and their products involved in tissue inflammation. On the one hand, some studies suggest that HIFs play an important functional role in enabling innate to function in a hypoxic micro-environment. For example, bacterial killing is critically regulated by HIF1A in myeloid phagocytes [21]. Similarly, a recent study demonstrates that lipopolysaccharide-induced succinate stabilizes HIF1A and identifies succinate as a metabolite in innate immune signaling, which enhances interleukin- $1 \beta$ production during inflammation via HIF [19]. On the other hand, many transcriptional targets of HIFs are anti-inflammatory, for example, the extracellular signaling molecule adenosine. As such, gene-targeted mice for the Adora $2 \mathrm{~b}$ adenosine receptor are more prone to inflammation [22]. Also, many studies indicate that deletion of HIFs in models of acute or chronic inflammation is involved in a negative feedback loop dampening innate or adaptive immune responses [23-25]. As such, it is tempting to speculate that HIF could potentially function to enhance bactericidal effects of innate

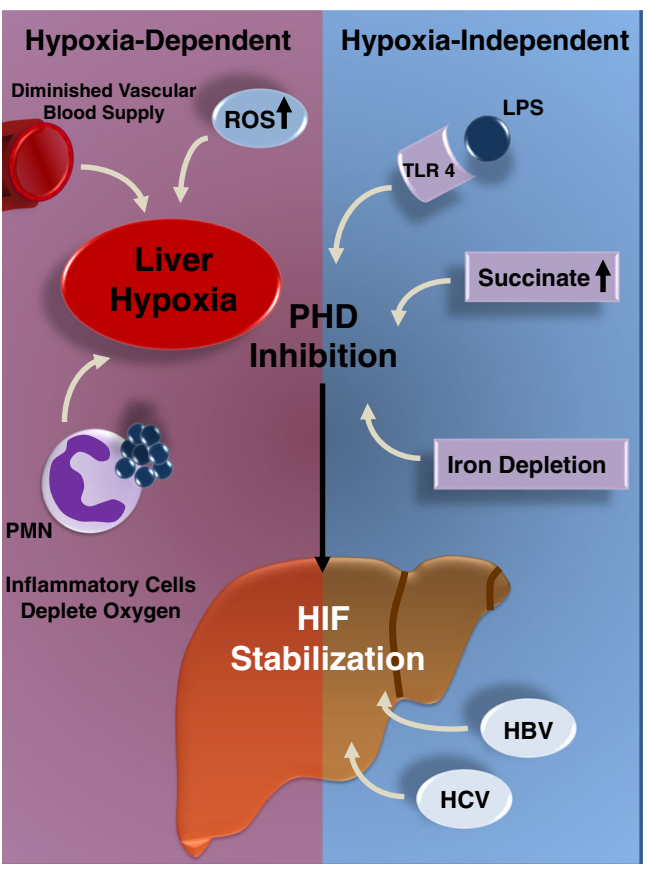

Fig. 1 Hypoxia-dependent and hypoxia-independent mechanisms responsible for hepatic stabilization of hypoxia-inducible factor HIF. Under normoxic conditions, HIF is hydroxylated via prolyl hydroxylases (PHDs) and thereby target HIF for proteasomal degradation. Hypoxia-dependent and hypoxia-independent pathways can result in PHD inhibition and concomitant HIF stabilization during liver disease. The left side of the figure displays conditions of liver disease that directly lead to a hypoxic microenvironment. During conditions of liver disease, imbalance in supply and demand for metabolitesparticularly oxygen - can lead to hepatic hypoxia, including diminished supply with oxygen through the vasculature. Hypoxia-associated increases in reactive oxygen species (ROS) have been reported to lead to PHD inhibition. Similarly, infiltrating inflammatory cells can deplete the microenvironment from oxygen, for example, poly-morphonuclear neutrophils (PMN) undergoing PMN burst [15]. Hypoxia-independent pathways leading to PHD inhibition include activation of toll-like receptors (particularly TLR4) through bacterial products, such as lipopolysaccharide (LPS). Accumulation of the citrate cycle intermediate succinate can function as a PHD inhibitor [181]. Iron depletion of the micro-environment for example through bacterial siderophores can lead to PHD inhibition and HIF stabilization [182]. Moreover, elevated transcription of HIF can be a direct effect during infection with hepatitis $\mathrm{B}(\mathrm{HBV})$ or hepatitis $\mathrm{C}(\mathrm{HCV})$ virus

immune cells, while simultaneously functioning to prevent immune-mediated collateral tissue damage. These findings would indicate that HIF activators could be potent therapeutics to dampen inappropriate liver inflammation, such as occurs in the setting of ischemia and reperfusion injury [26-28].

Overall, the HIF-mediated adaptive responses to tissue hypoxia and other micro-environmental changes are critical for tissue recovery and repair from injury; and thus, HIF stabilization confers hepato-protection during acute liver damage. However, in chronic liver disease, prolonged HIF activation may be detrimental through accelerating fibrosis development, facilitating viral replication, and promoting tumor cell growth and metastasis. The following sections will (i) summarize the clinical 
evidence for the involvement of HIFs in a variety of acute and chronic liver diseases, (ii) discuss the current understanding and knowledge gaps of the mechanistic involvement of HIF $1 \alpha$ and HIF $2 \alpha$ in the disease development and progression (Table 1), and (iii) highlight the potentials of activating or inhibiting HIFs as therapeutic interventions to treat various liver diseases (Table 2).

\section{HIF in ischemia-reperfusion (IR)-induced acute liver damage}

IR is characterized as a restriction of blood supply to an organ followed by reperfusion and re-oxygenation of blood vessels. Restriction of blood supply causes tissue hypoxia and imbalance of metabolic supply and demand [26]. Reperfusion is usually accompanied by tissue damage and inflammatory responses. IR liver injury occurs in a number of clinical settings such as hemorrhagic shock, trauma, liver surgery, and liver transplantation [29], which is the only effective treatment for end-stage liver diseases. Associated with causing liver dysfunction and even liver failure, IR liver injury represents the major challenge of liver transplantation and significantly contributes to postoperative morbidity and mortality [30]. There are two types of IR liver injury caused by warm IR and cold IR. The warm IR develops during liver transplantation surgery, shock, or trauma. The cold IR occurs during ex vivo organ preservation. The ischemia time is a good predictor of patient and graft survival. During surgery, the warm ischemic time ranging from 15 to $50 \mathrm{~min}$ will result in significant morbidity [31]. A meta-analysis of 26 studies revealed that both patient and graft survival declines significant when the cold-ischemia time exceeds $12.5 \mathrm{~h}$ [32]. It has also been reported that cold-ischemia time longer than $6 \mathrm{~h}$ results in nearly threefold higher risk of graft failure [33]. Due to organ shortage, currently only one third of the patients waiting for a liver transplant actually undergo the procedure (US Department of Health and Human Services. Organ Procurement and Transplantation Network (online), http://optn.transplant.hrsa. gov/data/ (2012). To cope with this issue, criteria for donor organs have been extended to include those from older, steatotic, and non-heart-beating donors. These "marginal" organs will be more prone to damage during procurement, preservation, and surgery and thus are particularly susceptible to IR injury.

Complex molecular and cellular mechanisms account for IR liver injury. Microcirculation dysfunction occurs at early time points as result of vasoconstriction and the swelling of sinusoidal endothelial cell and Kupffer cell. The narrowing of sinusoids entraps leukocytes, further hindering blood flow and causing tissue hypoxia. In such settings, the "master regulator" of cellular response to hypoxia, HIF, is stabilized. The HIF activation is likely an adaptive response to IR. Studies using pharmacological approaches to stabilize HIFs have revealed their protective function during IR liver injury [34-36]. The underlying mechanism of the protection involves HIFinduced transcriptional regulation of myriad of genes that regulate multiple pathways of cell adaptive responses to hypoxia, including reprogramming of cellular energy metabolism (Pdk1, Glut-1, carbonic anhydrase (CA4/9)) and promoting angiogenesis ((Vegf, nitric oxide synthase (NOS)). Moreover, HIFs play an important role in the upregulation of cytoprotective molecules, such as heme oxygenase (Hmox-1), heat-shock proteins (HSPs), and erythropoietin. It has been reported that HIF- $1 \alpha$ suppresses hepatocellular carcinoma cell apoptosis through upregulating Bcl-2 and inhibiting the expression and mitochondrial release of $\mathrm{Omi} / \mathrm{HtrA} 2$, a serine protease involved in capase-dependent apoptosis [37]. It has also been demonstrated that HIF-1 $\alpha$ can reduce palmitic acid-induced lipotoxicity and ER stress in hepatocytes [38]. These findings suggest that the role of HIF in promoting hepatocyte survival may be an important protective mechanism during I/R liver injury.

It has been reported that prolyl hydroxylase-1 (PHD1) negatively regulates IkappaB kinase-beta and thus NF- $\mathrm{KB}$ activity [39], suggesting that inhibiting PHD1 could promote cell survival through enhancing NF- $\mathrm{KB}$ activation. In fact, it has been shown that $\mathrm{PHD}^{-/-}$mice are less susceptible to the development of colitis due to decreased epithelial cell apoptosis and enhanced epithelial barrier function [40]. There have been two studies of the role of PHD1 in liver injury, and the findings are consistent with the notion that PHD1 inhibition promotes cell survival. One study demonstrated that $\mathrm{PHD}^{-/-}$mice were
Table 1 Comparing the roles of HIF $1 \alpha$ and HIF $2 \alpha$ in various liver diseases

\begin{tabular}{lll}
\hline Liver disease & Role of HIF1 $\alpha$ & Role of HIF2 $\alpha$ \\
\hline I/R liver injury & Protective $[34,35,41]$ & Protective [46] \\
NAFLD & Not clear & Contributes to steatosis [13, 77, 78] \\
ALD & Controversial [92, 93] & Not been studied \\
Liver fibrosis/cirrhosis & Pro-fibrogenic [102, 104, 105] & Not been studied \\
Viral hepatitis & Contributes to disease progression & Contributes to disease progression [122, 123] \\
HCC & {$[14,115,121]$} & Controversial [133, 146, 147] \\
& Contributes to tumorigenesis & \\
\hline
\end{tabular}


Table 2 Examples of ongoing clinical trials related to HIF and liver diseases

\begin{tabular}{|c|c|c|c|}
\hline Drug & Patient population & Purpose of study & $\begin{array}{l}\text { Clinical } \\
\text { trials.gov } \\
\text { number }\end{array}$ \\
\hline $\begin{array}{l}\text { EZN-2968 (anti-sense oligonucleotide } \\
\text { inhibitor of HIF-1 } \alpha, \mathrm{NCI} \text { ) }\end{array}$ & $\begin{array}{l}\text { Patients diagnosed with liver cancer who } \\
\text { have not responded to standard } \\
\text { treatments }\end{array}$ & Determine the safety and effectiveness (Phase I) & $\begin{array}{r}\text { NCT01120288 } \\
\text { (completed) }\end{array}$ \\
\hline $\begin{array}{l}\text { (HIF-1 } \alpha \text { Analysis, Northwestern } \\
\text { University) }\end{array}$ & Patients diagnosed with $\mathrm{HCC}$ & $\begin{array}{l}\text { Compare levels of HIF- } 1 \alpha \text { expression in HCC } \\
\text { tumor explants }\end{array}$ & $\begin{array}{c}\text { NCT00866957 } \\
\text { (recruiting) }\end{array}$ \\
\hline (PET, Siemens Molecular Imaging) & $\begin{array}{l}\text { Cancers of head and neck, lung, liver, } \\
\text { rectal, or cervix }\end{array}$ & $\begin{array}{l}\text { PET imaging to detect tumor hypoxia regions } \\
\text { (phase II) }\end{array}$ & $\begin{array}{r}\text { NCT01075399 } \\
\text { (completed) }\end{array}$ \\
\hline $\begin{array}{l}\text { RO7070179 (HIF-1 } \alpha \text { mRNA } \\
\text { antagonist, Hoffmann-La Roche) }\end{array}$ & Patients diagnosed with HCC & $\begin{array}{l}\text { Proof-of-mechanism of HIF-1 } \alpha \text { inhibition by a } \\
\text { decrease of mRNA (Phase } 1 \mathrm{~b} \text { ) }\end{array}$ & $\begin{array}{l}\text { NCT02564614 } \\
\text { (recruiting) }\end{array}$ \\
\hline Bevacizumab (anti-VEGF mAb, NCI) & $\begin{array}{l}\text { Primary HCC, advanced } \mathrm{HCC} \text {, localized } \\
\text { unresectable HCC, recurrent primary } \\
\text { HCC }\end{array}$ & $\begin{array}{l}\text { (Evaluating the efficacy of combining bevacizumab } \\
\text { with erlotinib in treating advanced HCC, } \\
\text { Phase II) }\end{array}$ & $\begin{array}{r}\text { NCT00365391 } \\
\text { (completed) }\end{array}$ \\
\hline $\begin{array}{l}\text { Molecular Adorbent Recirculating } \\
\text { System (MARS, Medical University } \\
\text { of Vienna) }\end{array}$ & $\begin{array}{l}\text { Hypoxic hepatitis, ischemic hepatitis, shock } \\
\text { liver, hypoxic liver injury, acute liver } \\
\text { failure }\end{array}$ & $\begin{array}{l}\text { Determine whether MARS improves hepatic } \\
\text { hemodynamics and functions in severe hypoxic } \\
\text { hepatitis (Phase II) }\end{array}$ & NCT01690845 \\
\hline $\begin{array}{l}\text { OXY111A (HIF- } 1 \alpha \text { inhibitor, } \\
\text { University of Zurich) }\end{array}$ & $\begin{array}{l}\text { HCC, cholangiocarcinoma, pancreatic } \\
\text { neoplasms, colorectal neoplasms }\end{array}$ & $\begin{array}{l}\text { Evaluate safety and determine the maximum } \\
\text { tolerated dose of OXY111A (Phase I and II) }\end{array}$ & $\begin{array}{l}\text { NCT02528526 } \\
\text { (recruiting) }\end{array}$ \\
\hline
\end{tabular}

protected against acute I/R liver injury [41]. Moreover, knockdown of PHD1 in hepatocytes conferred tolerance of the cells to hypoxia due to reduced oxidative stress. Another study demonstrated that liver regeneration was significantly enhanced in $\mathrm{PHD}^{-/}$mice compared to WT mice. This effect was due to increased hepatocyte proliferation with increases in c-myc transcriptional activity [42]. The results from both studies suggest that short-term PHD1 inhibition may be a novel therapy to attenuate or prevent I/R liver injury and to facilitate liver regeneration after surgical resection.

Furthermore, hypoxia-driven increases in extracellular adenosine signaling represent an important pathway mediating the protective effect of HIFs during IR liver injury. In the extracellular compart, adenosine can function as a signaling molecule. It mainly stems from the breakdown of extracellular nucleotides and nucleosides, such as ATP, ADP, or AMP [43, 44]. Several studies have shown that during conditions of ischemia and reperfusion injury, the enzymatic system that controls extracellular nucleotide generation is transcriptionally induced, including the enzymes CD39 (ATP/ADP conversion to AMP) and CD73 (AMP conversion to adenosine) [45-47]. While CD39 is transcriptionally controlled by the transcription factor SP1, CD73 is a direct HIF target gene (Fig. 2). Moreover, other studies demonstrate that adenosine receptor signaling is increased during conditions of limited oxygen availability due to HIF-dependent induction of the A2A and A2B adenosine receptors [48, 49]. Such liver protective pathways can for instances be harnessed by hypoxic preconditioning, leading to a concomitant induction of the Adora2b adenosine receptor subtype [50], a known transcriptional target of HIF $1 \alpha[51,52]$. Other studies implicate the Adora2a adenosine receptor in liver protection [53], which is a known target gene of HIF2 $\alpha$ [54]. Again, other studies implicate HIF-controlled transcriptional repression of adenosine transporters in hypoxia-elicited adaptation and tissue protection $[55,56]$. As such, many studies provide a rational for hypoxia-elicited increases in adenosine generation and signaling as an important endpoint in liver protection during ischemia and reperfusion injury (Fig. 2).

Overall, pre-clinical studies have provided strong evidence highlighting the therapeutic potential of HIF stabilization in attenuation and prevention of IR liver injury. One approach is surgical preconditioning by clamping the hepatic artery, which has been shown to sufficiently activate HIF signaling pathway and promote cell survival $[57,58]$. A clinical trial of ischemic preconditioning induced by 10-min hiliar clamping demonstrated improved biochemical markers of liver function and increased HIF-1 $\alpha$ levels [59]. However, ischemic preconditioning in a surgical transplant setting is more challenging than pharmacological activation of HIFs. As such, pre-clinical and clinical studies are on-going to explore the efficacy of HIF modifiers. Iron chelator, mangafodipir, which inhibits PHDs, has been shown to activate HIF- $1 \alpha$ and mitigate IR liver injury in rats [34]. A PHD inhibitor, ethyl 3,4-dihyroxybenzoate, has been shown to activate HIF-1 $\alpha$ and its target Hmox-1, thereby inhibiting mitochondrial permeability transition and attenuating IR liver injury [36]. More recently, several promising pharmacologic HIF activators are being studied in patients for the treatment of renal anemia [60]. Similar studies evaluating the beneficial effects of HIF stabilization before or during liver transplantation are urgently needed. The use of pharmacological HIF activators could represent a novel therapeutic approach to significantly dampen hepatic ischemia and reperfusion injury and thereby contributing to improved outcomes during liver 


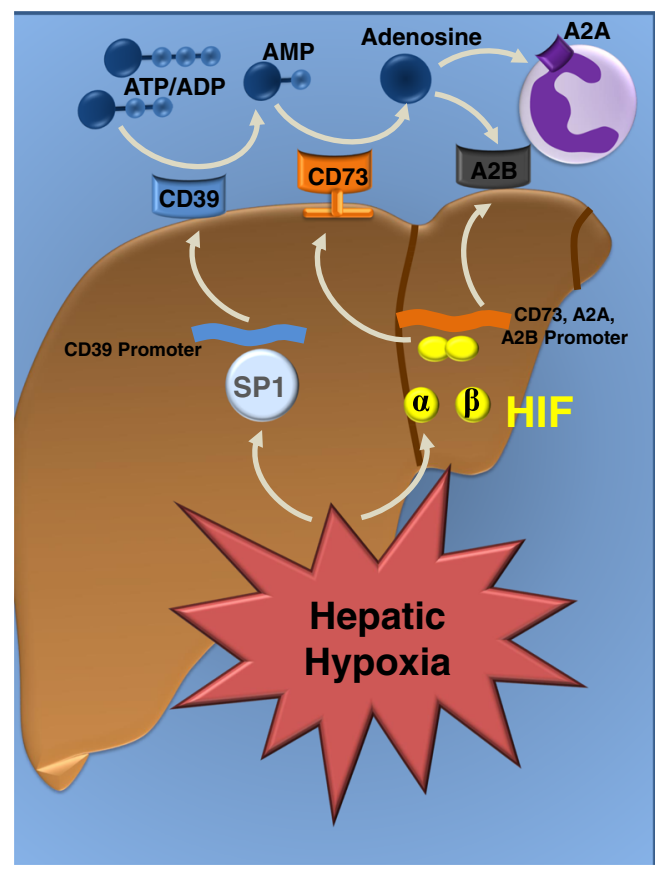

Fig. 2 Hypoxia-stimulated adenosine production and signaling during hepatic ischemia and reperfusion injury. During liver transplantation, ischemia and reperfusion injury of the liver graft results in profound hypoxia and concomitant increases in hypoxia-dependent signaling pathways. One of the main outcomes of these transcriptional programs is increased production and signaling of the extracellular signaling molecule adenosine. During liver injury, multiple cell types release nucleotides in the form of adenosine triphosphate (ATP) or adenosine diphosphate (ADP). ATP and ADP are enzymatically converted via CD39 to adenosine monophosphate (AMP), which in turn is converted to adenosine via the enzyme CD73 [49]. Conditions of hepatic hypoxia will result in the transcriptional induction of CD39 via the transcription factor SP1 [45] and of CD73 via the transcription factor hypoxiainducible factor HIF [47]. Similarly, the A2A and A2B adenosine receptors are transcriptionally induced by $\operatorname{HIF}[48,49]$. Many studies have implicated increased extracellular adenosine signaling in liver protection from ischemia and reperfusion injury [53]

transplantation. Similarly, clinical studies exploring adenosine signaling in the context of hepato-protection during liver transplantation have to be further explored.

\section{HIF and nonalcoholic fatty liver disease (NAFLD)}

NAFLD is becoming the most common chronic liver disease worldwide due to the epidemic increase of incidence of obesity, diabetes and metabolic diseases. It is estimated that NAFLD affects $9-37 \%$ of the population worldwide [61-63]. In the US, NAFLD affects $30 \%$ of the general population and about $90 \%$ of the morbidly obese individuals [64, 65]. NAFLD consists a range of disorders from simple fat accumulation in the liver (steatosis) to pathological nonalcoholic steatohepatitis. Steatosis is defined as deposition of triglycerides exceeding $55 \mathrm{mg}$ per gram of liver or the presence of triglycerides droplets in more than $5 \%$ of hepatocytes [66]. Hepatic triglycerides formation is attributable to three pathways, including diet, de novo lipogenesis, and fatty acid release from the adipose tissues. In the liver, free fatty acid is removed by oxidation in the mitochondria, stored as triglycerides lipid droplets or secreted as a constituent of very-lowdensity lipoproteins (VLDL). Steatosis arises from an imbalanced hepatic triglycerides acquisition and removal. For example, it is estimated that a typical American daily diet consisting $100 \mathrm{~g}$ of fat will result in $20 \mathrm{~g}$ of fat deposition in the liver, accounting for half of the total triglycerides content of an average liver. Although steatosis is benign initially, it represents a key step in the development of hepatitis with hepatocyte damage, infiltration of inflammatory leukocytes, and collagen deposition (fibrosis). In approximately 10 $30 \%$ of individuals with nonalcoholic steatohepatitis, the disease progresses into liver cirrhosis within 10 years [67]. Among liver cirrhosis patients, as high as $40-60 \%$ will develop hepatocellular carcinoma (HCC) $[68,69]$.

Hypoxia occurs in the development and progression of NAFLD as result of increased metabolic demands and oxygen consumption, as well as hepatic sinusoids constriction due to hepatocyte swelling and fibrotic scar accumulation [70-72]. Hypoxia has been associated with perturbation of lipid homeostasis. Hypoxic stress of cells or tissues results in lipid accumulation [73, 74]. It is also reported that hypoxia induces genes involved in lipid synthesis, storage, and uptake $[75,76]$. These findings, as well as the observation of HIF stabilization in animals and patients with NAFLD, implicate a role for HIF in regulating hepatic lipid metabolism. The majority of the published reports support the hypothesis that HIFs, HIF$2 \alpha$ in particular, promote hepatic steatosis.

It has been reported that deletion of both PHD2 and PHD3 in the liver results in severe hepatic steatosis with increased expression of HIFs [77]. Mice with hepatocyte-specific deletion of VHL, resulting in the overexpression of both HIF- $1 \alpha$ and HIF-2 $\alpha$, also exhibit increased hepatic lipid accumulate compared with WT mice [78]. Similar to the VHL knockout mice, hepatic steatosis is also observed in another mouse model of HIF overexpression, in which HIF- $1 \alpha$ and HIF- $2 \alpha$ variants that cannot be hydroxylated were introduced [79]. Between the two isoforms, HIF- $2 \alpha$ is shown to play a more important role in regulating hepatic lipid metabolism. In the PHD2/PHD3 double knockout mice, it is demonstrated that HIF- $2 \alpha$, but not HIF- $1 \alpha$, is associated with steatosis [77]. Similarly, in the VHL-deficient mice, deletion of HIF- $2 \alpha$, but not HIF- $1 \alpha$, attenuates hepatic steatosis, suggesting that HIF- $2 \alpha$ is the main promoter of steatosis [13, 78]. Although the direct molecular targets of HIF- $2 \alpha$ are not clear, the data demonstrate that HIF- $2 \alpha$-overexpressed mice exhibit increased expression of lipogenic genes (SREBP1c and FAS) and decreased expression of genes involved in fatty acid oxidation (PPAR $\alpha$ and carnitine palmitoyl-CoA transferase-1, Cpt1) $[13,78]$. 
Accumulating evidence suggests an important role of HIFs in the regulation of lipid metabolism and NAFLD development [80]. However, it remains unclear whether genes involved in lipogenesis, lipid storage, and fatty acid oxidation are direct transcriptional targets of HIF $2 \alpha$ (or HIF-1 $\alpha$ ) or they are increased as an indirect effect of HIF stabilization. More detailed molecular studies to address this question are warranted to elucidate the mechanism of HIF-mediated regulation of lipid metabolism. The knowledge gained from such studies will substantiate the involvement of HIFs in the pathogenesis of NAFLD and provide the basis for developing HIF-targeted therapeutic strategies.

\section{HIF and alcoholic liver disease (ALD)}

Alcohol abuse is a leading cause of chronic liver disease that affects millions of people worldwide. ALD encompasses a range of disorders from steatosis to alcoholic hepatitis, cirrhosis, and HCC. Alcohol-related liver cirrhosis accounts for nearly half of liver cirrhosis-associated deaths in the US [81, 82]. Among patients with alcohol-induced advanced liver cirrhosis, approximately $10 \%$ will develop HCC [83]. Although the majority of heavy drinkers ( $>90 \%$ ) develop steatosis, only about one third will develop cirrhosis, suggesting the involvement of other risk factors. For example, females are more susceptible to ALD than males, probably due to estrogen, higher proportion of body fat, and lower levels of alcoholic dehydrogenase. As another risk factor, obesity accelerates cirrhosis development in ALD patients [84, 85]. Moreover, it is clearly shown that hepatitis B or C and alcohol drinking synergistically accelerate the disease progression to liver cirrhosis and HCC [86]. Aside from the direct hepatotoxic effect of ethanol metabolism, various hepatic non-parenchymal cells and their soluble products contribute to liver injury and inflammation during ALD. A better understanding of the pathogenesis is important for developing new therapies, which currently are limited to abstinence and corticosteroids.

After either acute or chronic ethanol, oxygen consumption by the liver is increased $[87,88]$ due to ethanol-induced hormones (e.g., catecholamine), metabolic demands, and oxidative stress [89]. The resulting liver tissue hypoxia is observed in animal models and in patients with ALD [89-91]. HIF stabilization has been reported in chronic alcoholics and in a murine model of ALD [92-94]. Alcohol-induced fatty liver shares similar clinical features and underlying pathogenesis with NAFLD. Therefore, it is likely that HIF- $2 \alpha$ contributes to the development of hepatic steatosis during ALD as in NAFLD. However, the role of HIF- $2 \alpha$ in the pathogenesis of ALD has not been investigated. Up to date, there are only two reports describing the involvement of HIF-1 $\alpha$ in alcohol-associated hepatic steatosis, and their findings are contradictory.

Both studies used the HIF- $1 \alpha^{\mathrm{f} / \mathrm{f}} / \mathrm{Alb}{ }^{\mathrm{Cre}}$ mouse, in which $\mathrm{HIF}-1 \alpha$ is deleted conditionally in hepatocytes. The earlier study demonstrated that compared with WT mice, those deficient of HIF-1 $\alpha$ developed reduced hepatic steatosis and hypertriglyceridemia [93]. Although the signaling pathway that mediates the downstream pro-steatotic function of HIF$1 \alpha$ was not a focus, this study demonstrated that monocyte chemotactic protein (MCP)-1 was an upstream activator that increased HIF-1 $\alpha$ protein expression and its DNA-binding activity. In contrast, the later study demonstrated that alcohol feeding led to enhanced hepatic steatosis and serum triglycerides when HIF-1 $\alpha$ was deleted in hepatocytes [92]. The data showed that lipogenic genes, such as acyl-CoA carboxylase (ACC)-1, fatty acid synthase (FAS), and stearoyl-CoA desaturase (SCD)-1 were expressed at higher levels in HIF$1 \alpha$-deficient than WT mice. These lipogenic genes are regulated by sterol regulatory element-binding protein (SREBP)-1c, which is repressed by differentiated embryo chondrocyte 1 (DEC1). DEC1 is known to be a transcriptional target of HIF-1 $\alpha$. In supporting the role of DEC1 in mediating the anti-steatotic function of $\mathrm{HIF}-1 \alpha$, the data demonstrated that DEC1 was elevated in alcohol-fed WT but not HIF-1 $\alpha$-deficient mice. Furthermore, DEC1expressing plasmid, as well as the PHD inhibitor dimethyloxaloylglycine (DMOG), was able to ameliorate steatosis in HIF-1 $\alpha$-deficient mice [92].

The discordant results obtained from the two studies may be due to differences in the experimental details, such as the dose of ethanol, gut microbiome differences of animals, and the choice of control mice. Additional studies are warranted to reconcile the discrepancies and more importantly, to elucidate the molecular signaling pathways that mediate the involvement of HIFs. Furthermore, these two reported studies only focused on investigating the role of HIFs in alcohol-induced steatosis, which is an early manifestation of ALD. However, the disease progresses to much more severe forms including steatohepatitis, cirrhosis, and HCC. It is important for future studies to elucidate whether and how HIFs may play a role in the disease progression.

\section{HIF and liver fibrosis/cirrhosis}

Chronic liver injury and inflammation caused by viral hepatitis B or C infections, alcohol abuse, NAFLD, and biliary obstruction often results in tissue fibrosis [95]. Fibrosis is part of a normal wound-healing response to tissue injury. However, repeated injury causes chronic inflammation, matrix deposition, and angiogenesis, which leads to progressive fibrosis. In some patients, liver fibrosis progresses to cirrhosis, in which hepatocytes are replaced by scar tissue with excess collagen produced by hepatic stellate cells. Advanced liver cirrhosis is characterized by portal hypertension and disruption of hepatic architecture, which often result in liver failure requiring liver transplantation [95]. As an end-stage liver disease, cirrhosis is ranked as the tenth leading cause of death in the Western 
world [96]. It is estimated that a 10-year mortality rate of established cirrhosis is 34-66\% [97]. Moreover, liver cirrhosis is clearly a risk factor for the development of $\operatorname{HCC}[98,99]$.

Liver fibrosis causes an increased resistance to blood flow [100], which together with sinusoidal capillarization and sinusoidal obstruction syndrome causes tissue hypoxia [101]. Interestingly, hypoxic areas co-localize with those of fibrosis, suggesting a link between hypoxia and fibrogenesis [6]. Moreover, HIF stabilization has been reported in experimental models of liver fibrosis [102]. These observations suggest that HIFs may contribute to fibrosis development. In support of this hypothesis, clinical studies of human cirrhotic liver reveal that HMOX-1 and VEGF, well-known targets of HIFs, are detected in cells of fibrotic septa $[6,10,103]$.

Although the role of HIF- $2 \alpha$ has not been investigated, the pro-fibrogenenic effects of HIF- $1 \alpha$ in multiple cell types of the liver have been reported in experimental models. $\mathrm{CCl}_{4}$-induced fibrosis is a commonly used model, in which mice are treated with $\mathrm{CCl}_{4}$ twice weekly for at least 5 weeks. In this model, liver fibrosis develops as result of chronic tissue damage and wound healing. Surgical ligation of the bile duct represents another commonly used model to induce obstructive cholestatic liver injury, which causes inflammation and leads to liver fibrosis after 21 days. It has been demonstrated that compared with WT mice, those with hepatocyte-specific HIF- $1 \alpha$ deletion developed reduced liver fibrosis when subjected to bile duct ligation or chronic $\mathrm{CCl}_{4}$ treatment $[102,104]$. Myeloid cell-specific deletion of HIF-1 $\alpha$ or HIF-1 $\beta$ suppresses bile duct ligationinduced hepatic expression of Pdgf-b, alpha-smooth muscle actin, and type I collagen, all markers of fibrosis [105]. Hypoxic exposure of hepatic stellate cells isolated from WT and HIF- $1 \alpha$-deficient mice revealed that the expression of several pro-fibrogenic factors, such as Vegf, placenta growth factor, macrophage migration inhibition factor, CCR1, and CCR5, are dependent on HIF-1 $\alpha$ [105].

HIF-induced fibrogenesis can be a direct or indirect effect of HIF transcriptional activity. Many pro-fibrogenic factors, such as Vegf, Mcp-1, plasminogen activator inhibitor-1, Pdgf-a, Pdgf-b, fibroblast growth factor (Fgf)-2, and MMPs are transcriptional targets of HIFs. Moreover, adenosine production and its receptor signaling are regulated by HIFs, and adenosine signaling plays a role in promoting liver fibrosis. It has been shown that activation of Adora2A induces collagen production by hepatic stellate cells [105], and inhibition or deletion of Adora2A suppresses liver fibrogenesis $[106,107]$. The pro-fibrotic function of adenosine is also dependent on Adora2B, as its antagonist (MRS1754) has been shown to reduce liver fibrosis [108].

Accumulating evidence now suggests a tight link between angiogenesis and fibrogenesis, both occur during chronic inflammatory liver diseases. Many factors that are upregulated during angiogenesis also have profibrogenic effects, such as Vegf, Fgf2, and Pdgf. Therefore, the role of HIFs in promoting angiogenesis may indirectly promote liver fibrosis. Another indirect mechanism for the pro-fibrotic function of HIFs lies in their role in promoting inflammatory leukocytes accumulation in the liver. Infiltration of inflammatory cells require the interaction between CXCR4 and its ligand, stromal cell-derived factor-1 (SDF-1), both are HIF target genes [109]. In other tissues, it has been demonstrated that HIF-1-dependent epithelial-mesenchymal transition (EMT) contributes to fibrogenesis. The mechanism involves HIF-induced upregulation of lysyl oxidases, Snaill, and Twist expression $[110,111]$.

Therapy for fibrosis/cirrhosis is limited. Because of the pro-fibrotic role HIFs, therapeutic inhibition of HIF- $1 \alpha$ and/ or HIF- $2 \alpha$ may attenuate fibrosis and slow its progression to cirrhosis and HCC. However, HIF stabilization could also improve ischemic disorders associated with cirrhosis. As such, PHD inhibitors have been proposed for the treatment of fibrosis. A recent study suggests that different HIF target genes respond differently to PHD inhibitors [77]. Thus, it is possible to design PHD inhibitors that induce erythropoietin without significantly upregulating pro-fibrotic genes. To achieve this, a better understanding of the target genes that mediate the pro-fibrotic effect of HIFs is necessary.

\section{HIF and viral hepatitis}

Hepatitis B virus (HBV) is a member of the hepadnavirus family. HBV infection affects 350-400 million people, accounting for $5 \%$ of the world population [112]. The majority of infected people are Asian (75\%), whereas the prevalence is low in Western countries $(<1 \%)$ [113]. Hepatitis $C$ virus (HCV) is a single-stranded RNA virus that infects and replicates in hepatocytes. HCV infection affects 180 million people worldwide with higher prevalence in Japan, Europe, and the US than other regions [112]. As a major cause of acute and chronic liver injury, viral hepatitis often leads to serious endstage liver diseases such as cirrhosis and HCC [114]. Chronic HBV infection has been shown to increase the risk of HCC development by 5 - to 100 -fold. Similarly, HCV infection is associated with 15- or 20-fold increase in the risk for developing HCC. In fact, more than $80 \%$ of HCC patients has $\mathrm{HBV}$ or HCV infection [113]. Although vaccination prevents new cases, eradication of $\mathrm{HBV}$ in infected individuals has not been effective. Recently developed HCV protease inhibitors can efficiently eliminate the virus in the vast majority of patients. However, patients with hepatitis-associated cirrhosis remain at high risk of developing HCC. Liver transplantation is usually required once HCC occurs; however, with a high cancer recurrent rate, "re-transplantation" is necessary. Therefore, it remains important to identify new therapeutic targets in order to develop strategies to ameliorate liver injury caused by viral hepatitis and slow down the disease progression.

HIF- $1 \alpha$ and HIF- $2 \alpha$ stabilization has been observed in $\mathrm{HBV}$ - or HCV-infected cells and in liver biopsies from 
patients with chronic viral hepatitis [7, 9, 115]. Moreover, HIF- $1 \alpha$ polymorphisms are significantly associated with the development of HBV-related HCC [116]. These observations suggest a role for HIFs in the pathogenesis of viral hepatitis and/or its progression to liver cirrhosis and HCC.

Numerous studies have demonstrated that $\mathrm{HBV}$ and $\mathrm{HCV}$ can promote HIF protein stability and transcriptional activity under normoxia. The hepatitis B viral X protein $(\mathrm{HBx})$, which is indispensable for viral replication, can directly interact with the bHLH/PAS domain of HIF $\alpha$ subunit, thereby decreasing its binding with $\mathrm{pVHL}$ and preventing degradation [117]. The carboxy terminus of HBx was found to be critical in activating HIFs [118]. Aside from directly stabilizing HIFs, HBx induces HDAC1 and metastasis-associated protein 1, which inhibit HIF- $1 \alpha$ association with PHDs and thus stabilize HIFs [119]. Moreover, HBx is reported to activate MAPK pathway and in turn activate HIF-1 $\alpha$ [120]. HCV-induced HIF stabilization is mainly due to $\mathrm{HCV}$-induced oxidative stress and calcium signaling, which cause the activation of NF-kB and STAT3 [12].

Evidence suggests that HIFs may directly promote viral replication. It has been reported that $\mathrm{HCV}$ replication is augmented under hypoxia, and that inhibition of HIF- $1 \alpha$ suppresses viral replication $[14,121]$. HIFs may promote viral transmission and replication in hepatocytes through modifying cell permeability and energy metabolism. It is reported that HIF-induced VEGF production depolarizes hepatocytes and facilitates viral entry [122, 123]. HIF stabilization enhances cell survival, which indirectly promotes viral infection. HCV is known to impair mitochondrial oxidative phosphorylation; however, survival of infected cells is preserved by increased glycolysis, an adaptive response mediated by HIF-1 $\alpha$ [115]. It is also reported that HIF- $1 \alpha$ stabilization modulates tight junction proteins and promotes migration of HCV-infected cells [14].

Although some experimental data support a role for HIFs in viral replication and cellular responses to viral infection, the transcriptional targets involved remain to be elucidated. Aside from a role in viral hepatitis, HIFs are likely involved in the disease progression. HBx is strongly implicated in promoting angiogenesis, which is critical in fibrosis and cancer development. This effect of HBx is mediated by its induction of HIF stabilization and transcriptional activation of angiogenic factors such as VEGF [9]. Moreover, HIF-induced adenosine production and its signaling may impede host anti-viral immune responses, owing to the anti-inflammatory and immunosuppressive effects of adenosine $[124,125]$. These observations suggest that HIF may serve as an important therapeutic target to inhibit viral replication, boosting anti-viral immunity, and curbing the progression of viral hepatitis to more severe forms of liver disease.

\section{HIF and hepatocellular carcinoma (HCC)}

$\mathrm{HCC}$ is one of the most common cancers with more than half a million new cases occurring worldwide each year. Because of its poor prognosis and lack of treatment options, $\mathrm{HCC}$ ranks as the fifth most common cause of death in men and the ninth in women [126]. The majority of the HCC cases $(>80 \%)$ are associated with chronic hepatitis $\mathrm{B}$ and $\mathrm{C}$ infection occurring in less developed countries of East Asia and sub-Saharan Africa $[127,128]$. However, in the past 20 years, the incidence of HCC in developed countries has been increasing. For example, the annual incidence in the US has increased about $80 \%$ in recent years [129]. HCC arises from liver cirrhosis, which is progressed from chronic liver diseases, including NAFLD, ALD, and viral hepatitis. Clinical observations reveal that liver cirrhosis is present in nearly $80 \%$ of patients with $\mathrm{HCC}$, representing the most important risk factor for HCC development $[98,99]$. Current treatment options for HCC are very limited. A small number of patients $(15 \%)$ with early stage of the disease may be cured by liver resection or transplantation. However, in about half of the patients, tumor recurrence and metastases occur post-resection [130, 131]. The majority of the patients present with advanced HCC, and it is refractory to chemotherapy. A multikinase inhibitor, sorafenib, is currently the only first-line chemotherapy that has been shown to improve overall survival for approximately 3 months. Therefore, it is important to better understand the pathogenesis of HCC in order to develop novel therapeutic strategies.

Both HIF- $1 \alpha$ and HIF- $2 \alpha$ have been observed to be expressed at higher levels in HCC tissues than those in matched, non-tumor-surrounding tissues $[5,8,132]$. The high expression levels of HIF- $1 \alpha$ or HIF- $2 \alpha$ have been correlated with worse tumor grade, venous invasion, intrahepatic metastasis, and capsule infiltration [8, 133, 134]. HIF- $1 \alpha$ and/or HIF- $2 \alpha$ stabilization is a poor prognostic marker, as it is associated with shorter disease free period and lower overall survival rate [135-137]. Furthermore, genetic variations of HIF$1 \alpha$ have been associated with higher risk of development and prognosis of HCC and could serve as biomarkers [138, 139]. These clinical observations strongly suggest a pathological role of HIFs in HCC development and progression.

Multiple factors contribute to the stabilization of HIFs during HCC development. HCC typically arises in the condition of cirrhosis with reduced vascularization, which leads to hypoxia and HIF stabilization [140]. HIFs can also be activated by $\mathrm{HBV}$ and $\mathrm{HCV}$, which are major causes of HCC. In support of this, in the majority of tumor specimens from HBV-related HCC patients, increased expression of HIF- $1 \alpha$ was observed and the level correlates with the expression of HBx [141]. The mechanistic involvement of HIFs in HCC development stems from their gene transcriptional activities. Many HIF target genes play critical role in the key processes of tumorigenesis, such as cell proliferation, glucose metabolism, angiogenesis, invasion, and metastasis $[142,143]$. HIF- $1 \alpha$ induces growth factors, including TGF $\alpha$ and IGF-2, which promote cell proliferation and survival [144]. HIF- $1 \alpha$ directly binds to the 
promoter of Forkhead box M1 (FoxM1), a transcription factor that promotes proliferation in HCC [145]. The role of HIF-2 $\alpha$ in HCC is less clear, and there have been conflicting reports. Some studies show that HIF- $2 \alpha$ expression correlates with the progression of HCC [133]. However, recent evidence also supports a possible tumor suppressor role for HIF- $2 \alpha$ in HCC [146, 147].

Metabolic re-progamming from oxidative phosphorylation to aerobic glycolysis, termed the Warburg effect, is a common characteristic and survival mechanism of cancer cells. Key enzymes that contribute to the Warburg effect, such as PDK1 and lactate dehydrogenase A (LDHA), and the enzymes catalyzing glucose metabolism, such as phosphoglycerate kinase 1 (PGK1), hexokinase 1 and 2 (HK1/2), glyceraldehyde-3-phosphate dehydrogenase (GAPDH), phosphofructokinase (PFK), and the glucose transporters (GLUT-1 and GLUT-3), are all HIF-1 $\alpha$ target genes [148-152]. Angiogenesis is critical for tumor growth. HIF- $1 \alpha$ and HIF$2 \alpha$ transcriptionally activate VEGF, which is a potent angiogenic factor promoting endothelial cell proliferation, migration, and tube formation, especially in areas of hypoxia [153]. Aside from VEGF, HIF-1 $\alpha$ also induces SDF-1, angiopoietin 2 , placental growth factor, PDGF-B, and stem cell factor, all of which have proangiogenic activities $[154,155]$.

Tumor metastasis is the primary factor of poor prognosis in HCC. EMT is a critical step for tumor cells to acquire motility. HIF- $1 \alpha$ and HIF- $2 \alpha$ play important roles in EMT through downregulation of E-cadherin [132]. HIFs induce several genes that are E-cadherin repressors, such as Snail, Twist1, transcription factor 3 (TCF3), Zfhx1a, and Zfhx1b [132, 156-159]. In HBV- or HCV-positive HCC samples, a correlation between Snail and Twist induction and tumor metastasis has been established [160]. Moreover, HCV glycoproteins induce cancer cell migration via upregulation of Snail and Twist in an HIF-1 $\alpha$-dependent mechanism [14]. Extracellular matrix degradation by MMPs, such as MMP2 and MMP9, is another key mechanism in tumor metastasis $[161,162]$. HIF- $1 \alpha$ is an important transcription factor in upregulating the expression of MMPs [161, 163, 164]. It has been reported that HIF-1 silencing by siRNA reduces MMP2 and MMP9, thereby inhibiting migration and invasion of malignant gliomas [165]. However, there is also evidence supporting that HIF stabilization may improve tumor vessel functions and reduce the risk of metastasis. For example, in mice with haplodeficiency of PHD2, in which HIF- $2 \alpha$ is increased, the leakiness and distorted architecture of tumor vessels are improved [48]. The "normalized" vasculature is associated with reduced tumor invasiveness [48].

In summary, HIF stabilization and pathological contribution to $\mathrm{HCC}$ tumorigenesis have been demonstrated by numerous studies. The current evidence highlights the potential of inhibiting HIF as a therapeutic approach to treat HCC. Targeting HIF can be achieved by anti-sense oligonucleotides or small molecule inhibitors that promote HIF degradation or blocking HIF transcriptional activities. These strategies are currently being explored in both preclinical and clinical studies [166-169].

\section{HIF modifiers as therapies to treat liver diseases}

HIF has emerged as an important player in various liver diseases. Evidence supports a hepato-protective function of HIFs in acute liver injury, but a pathological role of HIFs in chronic liver disease. Although it appears to be paradoxical, the opposite involvement of HIFs in acute versus chronic liver diseases is consistent with their transcriptional activities. The target genes regulated by HIFs mediate adaptive responses to tissue stress and damage; however, the same genes that promote cell survival and proliferation and tissue repair lead to detrimental effects in chronic situations. Therefore, targeting HIF for therapies require very different approaches (Fig. 3). In situations of acute liver damage, such as IR liver injury, drug-induced liver failure, and acute hepatitis, HIF stabilization is desirable. Pharmacological inhibitors of PHDs, which stabilize HIFs, are

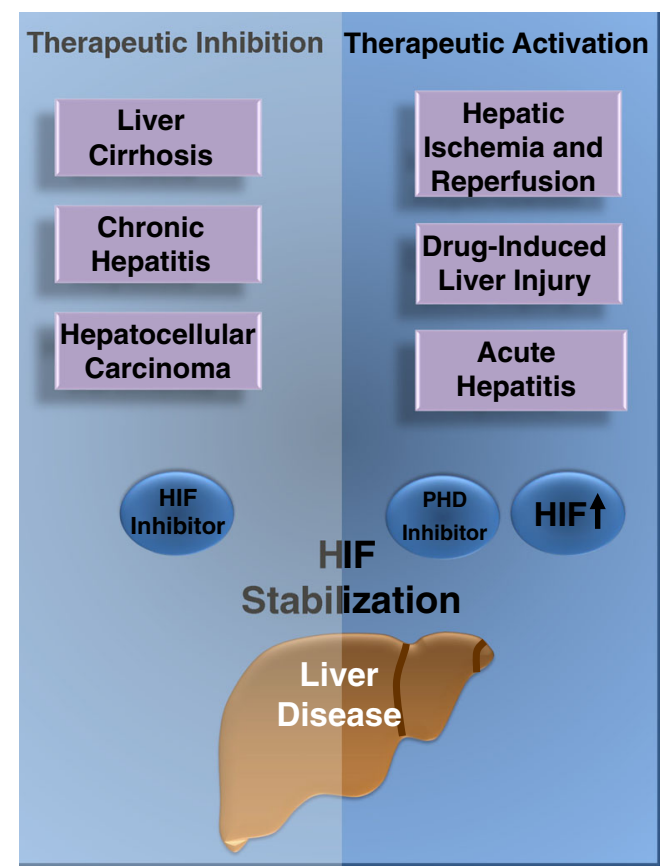

Fig. 3 Targeting hepatic hypoxia-signaling for the treatment of liver disease. Most evidence points towards a tissue protective role of hypoxia-inducible transcription factors (HIFs) during acute liver injury, while in conditions of chronic liver disease, inhibition of HIFs may be desirable. Pharmacologic approaches to enhance hepatic stabilization of HIFs during liver disease can be achieved by pharmacologic inhibitors of prolyl hydroxylases (PHDs). Such compounds are currently examined in clinical trials and could potentially provide liver protection during acute liver injury. Clinical trials providing direct evidence for this hypothesis have yet to be completed and published. During conditions of chronic liver disease, inhibition of HIF stabilization in the liver may provide a therapeutic benefit. For example, oligo-nucleotide inhibitors for HIF are in clinical trials for the treatment of liver cancer 
currently being explored as treatment for ischemia, acute kidney, lung, or heart injuries. For example, clinical trials are ongoing to evaluate the safety and efficacy of several PHD inhibitors, such as FG-4592, AKB-6548, GSK-1278863, in the treatment of anemia in patients with chronic kidney disease, cardiac ischemia, and those requiring dialysis [60]. These inhibitors may be beneficial in attenuating acute liver injury. For example, to prevent IR injury, HIF activators may be administered to liver donors prior to explantation of the liver or added into the perfusate of the explanted liver. Moreover, it has been reported that HIF is stabilized and contributes to liver regeneration through facilitating gluconeogenesis and promoting liver progenitor cell proliferation [170-172]. Thus, a beneficial effect of HIF stabilizers on major liver resection warrants investigation. During phase II clinical trial of a PHD inhibitor, FG-2216, hepatotoxicity was identified and determined to be an offtarget effect. A second-generation PHD inhibitor from FibroGen, FG-4592 was found to be safe during phase II and III clinical trials, and hepatotoxicity has not been reported for other PHD inhibitors in clinical trials. Moreover, based on the mechanism of action of the hydroxylase inhibitors and the evidence for the pro-survival effects of PHD inhibition and HIF stabilization, it is not likely that hepatotoxicity is a common side effect of this class of compounds [60].

In cases of chronic liver disease, cirrhosis and HCC in particular, inhibition of HIF may prove to be an effective treatment. In fact, targeting HIFs is being explored to treat HCC (examples are listed in Table 1). A HIF-1 $\alpha$ antisense oligonucleotide, EZN2968, has undergone phase I clinical trial in advanced malignancies. It reduced tumor size without improving clinical efficacy. This HIF- $1 \alpha$ antisense antagonist (under the name RO7070179) is now undergoing a phase $1 \mathrm{~b}$ trial in HCC patients who have failed at least one line of systemic therapy [168]. A fusion protein containing Gal4 and the C-terminal 41 residues of HIF- $1 \alpha$ transactivation domain (TAD-C) is reported to block the interaction of HIF-1 $\alpha$ with its co-activator p300/CBP. In xenograft models, this fusion protein attenuates expression of HIF- $1 \alpha$ target genes and reduces tumor growth [167]. Moreover, because of the involvement of HIFs in developing resistance to chemotherapy in HCC [173-178], HIF inhibitors can be given in combination with current therapies. For example, it has been shown that resistance to sorafenib can be overcome by EF24, which induces HIF-1 $\alpha$ degradation [179]. In vitro and in vivo studies reveal that knock-down of HIF- $2 \alpha$ with shRNA enhances the efficacy of sorafenib. [173, 178] Another study shows that treatment of antisense HIF- $1 \alpha$ synergizes with doxorubicin in suppressing tumor growth and angiogenesis [180]. Overall, preclinical studies strongly suggest HIF inhibition as a strategy to treat chronic liver disease, HCC in particular. However, cautions need to be taken in clinical studies. For example, it may be important to discontinue HIF inhibitor therapies in patients who are undergoing liver surgery for
HCC, as HIF inhibitors have the potential to exacerbate IR injury and inhibit liver regeneration.

\section{Concluding remarks}

HIF stabilization has been reported in animal models and clinical samples of various liver diseases. The functional consequences of HIF stabilization in liver diseases are beginning to be elucidated. Current evidence supports a hepato-protective function of HIFs in acute liver damage. In this case, the HIF transcriptional activities cause protection of cells, promotion of angiogenesis, and reprogramming of cellular energy metabolism. However, the same functions of HIFs result in a pathological role in hepatic lipid accumulation, fibrogenesis, and tumor progression during chronic liver diseases. These findings indicate that HIF activation is desirable in acute liver injury, but HIF inhibition can prevent and ameliorate chronic liver disease. The dichotomous role of HIFs indicates that the clinical effects of HIF modifiers may be time-sensitive and disease-dependent. For example, in HCC patients undergoing resection or liver transplantation, temporarily halting the use of HIF inhibitors but instead activating HIFs may be beneficial. The same strategy may be considered in liver cirrhosis patients suffering from an episode of acute-on-chronic liver injury.

With the emerging appreciation of the involvement of HIFs in various liver diseases, a challenge for basic research is to elucidate the underlying molecular mechanisms. It is important to uncover the transcriptional targets and signaling pathways that mediate the functions of HIFs in experimental models. Aside from hepatocytes, multiple cell types in the liver contribute to disease development. Therefore, it is also critical to investigate the protective or pathological role of cell-specific HIFs in various liver diseases. The knowledge gained from these studies will unravel the complex involvement of HIFs in liver disease and help the development of therapeutic strategies to modulate HIFs. HIF modifiers are actively being developed and evaluated clinically in treating ischemia and cancer. Although some of these compounds are undergoing clinical trials for liver transplantation and HCC, translational research endeavor should be further emphasized in the near future.

Acknowledgments This work was supported by U01AA021723 and R21AA022387 (to C.J.), R01DK104713 and R01DK50189 (to S.P.C.), and R01DK097075, R01HL092188, R01HL098294, P01HL114457, and R01HL119837 (to H.K.E.). The authors thank Shelley Eltzschig for her help in the preparation of the figures.

Open Access This article is distributed under the terms of the Creative Commons Attribution 4.0 International License (http:// creativecommons.org/licenses/by/4.0/), which permits unrestricted use, distribution, and reproduction in any medium, provided you give appropriate credit to the original author(s) and the source, provide a link to the Creative Commons license, and indicate if changes were made. 


\section{References}

1. Fitzmaurice C, Dicker D, Pain A et al (2015) The global burden of cancer 2013. JAMA Oncol 1:505-527

2. Ohh M, Park CW, Ivan M et al (2000) Ubiquitination of hypoxiainducible factor requires direct binding to the beta-domain of the von Hippel-Lindau protein. Nat Cell Biol 2:423-427

3. Maxwell PH, Wiesener MS, Chang GW et al (1999) The tumour suppressor protein VHL targets hypoxia-inducible factors for oxygen-dependent proteolysis. Nature 399:271-275

4. Lando D, Peet DJ, Gorman JJ et al (2002) FIH-1 is an asparaginyl hydroxylase enzyme that regulates the transcriptional activity of hypoxia-inducible factor. Genes Dev 16:1466-1471

5. Bangoura G, Yang LY, Huang GW, Wang W (2004) Expression of HIF-2alpha/EPAS 1 in hepatocellular carcinoma. World J Gastroenterol 10:525-530

6. Corpechot C, Barbu V, Wendum D et al (2002) Hypoxia-induced VEGF and collagen I expressions are associated with angiogenesis and fibrogenesis in experimental cirrhosis. Hepatology 35:1010 1021

7. Hu JL, Liu LP (2015) Yang SL et al. Hepatitis B virus induces hypoxia-inducible factor-2alpha expression through hepatitis B virus X protein. Oncol Rep

8. Li S, Yao D, Wang L et al (2011) Expression characteristics of hypoxia-inducible factor-1alpha and its clinical values in diagnosis and prognosis of hepatocellular carcinoma. Hepat Mon 11: $821-828$

9. Liu LP, Hu BG, Ye C et al (2014) HBx mutants differentially affect the activation of hypoxia-inducible factor-1alpha in hepatocellular carcinoma. Br J Cancer 110:1066-1073

10. Novo E, Povero D, Busletta C et al (2012) The biphasic nature of hypoxia-induced directional migration of activated human hepatic stellate cells. J Pathol 226:588-597

11. Jungermann K, Kietzmann T (2000) Oxygen: modulator of metabolic zonation and disease of the liver. Hepatology 31:255-260

12. Nasimuzzaman M, Waris G, Mikolon D, Stupack DG, Siddiqui A (2007) Hepatitis C virus stabilizes hypoxia-inducible factor 1alpha and stimulates the synthesis of vascular endothelial growth factor. J Virol 81:10249-10257

13. Qu A, Taylor M, Xue X et al (2011) Hypoxia-inducible transcription factor 2alpha promotes steatohepatitis through augmenting lipid accumulation, inflammation, and fibrosis. Hepatology 54: 472-483

14. Wilson GK, Brimacombe CL, Rowe IA et al (2012) A dual role for hypoxia inducible factor-1alpha in the hepatitis $\mathrm{C}$ virus lifecycle and hepatoma migration. J Hepatol 56:803-809

15. Campbell EL, Bruyninckx WJ, Kelly CJ et al (2014) Transmigrating neutrophils shape the mucosal microenvironment through localized oxygen depletion to influence resolution of inflammation. Immunity 40:66-77

16. Peyssonnaux C, Cejudo-Martin P, Doedens A et al (2007) Cutting edge: essential role of hypoxia inducible factor-1alpha in development of lipopolysaccharide-induced sepsis. J Immunol 178:75167519

17. Frede S, Stockmann C, Freitag P, Fandrey J (2006) Bacterial lipopolysaccharide induces HIF-1 activation in human monocytes via p44/42 MAPK and NF-kappaB. Biochem J 396: 517-527

18. Blouin CC, Page EL, Soucy GM, Richard DE (2004) Hypoxic gene activation by lipopolysaccharide in macrophages: implication of hypoxia-inducible factor 1alpha. Blood 103:1124-1130

19. Tannahill GM, Curtis AM, Adamik J et al (2013) Succinate is an inflammatory signal that induces IL-1beta through HIF-1alpha. Nature 496:238-242
20. Guzy RD, Hoyos B, Robin E et al (2005) Mitochondrial complex III is required for hypoxia-induced ROS production and cellular oxygen sensing. Cell Metab 1:401-408

21. Cramer T, Yamanishi Y, Clausen BE et al (2003) HIF-1alpha is essential for myeloid cell-mediated inflammation. Cell 112:645657

22. Ohta A, Sitkovsky M (2001) Role of G-protein-coupled adenosine receptors in downregulation of inflammation and protection from tissue damage. Nature 414:916-920

23. Aherne CM, Saeedi B, Collins CB et al (2015) Epithelial-specific $\mathrm{A} 2 \mathrm{~B}$ adenosine receptor signaling protects the colonic epithelial barrier during acute colitis. Mucosal Immunol 8:699

24. Clambey ET, McNamee EN, Westrich JA et al (2012) Hypoxiainducible factor- 1 alpha-dependent induction of FoxP3 drives regulatory T-cell abundance and function during inflammatory hypoxia of the mucosa. Proc Natl Acad Sci U S A 109:E2784-E2793

25. Colgan SP, Eltzschig HK (2012) Adenosine and hypoxiainducible factor signaling in intestinal injury and recovery. Annu Rev Physiol 74:153-175

26. Eltzschig HK, Eckle T (2011) Ischemia and reperfusion-from mechanism to translation. Nat Med 17:1391-1401

27. Aherne CM, Kewley EM, Eltzschig HK (1808) The resurgence of A2B adenosine receptor signaling. Biochim Biophys Acta 2011: 1329-1339

28. Eltzschig HK, Bonney SK, Eckle T (2013) Attenuating myocardial ischemia by targeting A2B adenosine receptors. Trends Mol Med 19:345-354

29. Howard TK, Klintmalm GB, Cofer JB et al (1990) The influence of preservation injury on rejection in the hepatic transplant recipient. Transplantation 49:103-107

30. Chen Y, Xie X (2012) Tacrolimus attenuates myocardium damage to the total hepatic ischemia-reperfusion via regulation of the mitochondrial function. J Surg Res 172:e47-e54

31. Serracino-Inglott F, Habib NA, Mathie RT (2001) Hepatic ischemia-reperfusion injury. Am J Surg 181:160-166

32. Stahl JE, Kreke JE, Malek FA, Schaefer AJ, Vacanti J (2008) Consequences of cold-ischemia time on primary nonfunction and patient and graft survival in liver transplantation: a meta-analysis. PLoS One $3: \mathrm{e} 2468$

33. Hong JC, Yersiz H, Kositamongkol P et al (2011) Liver transplantation using organ donation after cardiac death: a clinical predictive index for graft failure-free survival. Arch Surg 146:10171023

34. Ben MI, Mouchel Y, Pajaud J et al (2012) Pretreatment with mangafodipir improves liver graft tolerance to ischemia/ reperfusion injury in rat. PLoS One 7:e50235

35. Yang YY, Lee PC, Huang YT et al (2014) Involvement of the HIF1 alpha and Wnt/beta-catenin pathways in the protective effects of losartan on fatty liver graft with ischaemia/reperfusion injury. Clin Sci (Lond) 126:163-174

36. Zhong Z, Ramshesh VK, Rehman H et al (2008) Activation of the oxygen-sensing signal cascade prevents mitochondrial injury after mouse liver ischemia-reperfusion. Am J Physiol Gastrointest Liver Physiol 295:G823-G832

37. Xu Z, Chen X, Peng C et al (2012) Hypoxia-inducible factor1alpha suppressed hepatocellular carcinoma cell apoptosis through influencing on $\mathrm{Omi} / \mathrm{HtrA} 2$ expression and its releasing from the mitochondrion. Oncol Res 20:213-220

38. Yoo W, Noh KH, Ahn JH et al (2014) HIF-1alpha expression as a protective strategy of HepG2 cells against fatty acid-induced toxicity. J Cell Biochem 115:1147-1158

39. Cummins EP, Berra E, Comerford KM et al (2006) Prolyl hydroxylase-1 negatively regulates IkappaB kinase-beta, giving insight into hypoxia-induced NFkappaB activity. Proc Natl Acad Sci U S A 103:18154-18159 
40. Tambuwala MM, Cummins EP, Lenihan CR et al (2010) Loss of prolyl hydroxylase-1 protects against colitis through reduced epithelial cell apoptosis and increased barrier function. Gastroenterology 139:2093-2101

41. Schneider M, Van GK, Fraisl P et al (2010) Loss or silencing of the PHD1 prolyl hydroxylase protects livers of mice against ischemia/ reperfusion injury. Gastroenterology 138:1143-1154

42. Mollenhauer M, Kiss J, Dudda J et al (2012) Deficiency of the oxygen sensor PHD1 augments liver regeneration after partial hepatectomy. Langenbecks Arch Surg 397:1313-1322

43. Idzko M, Ferrari D, Eltzschig HK (2014) Nucleotide signalling during inflammation. Nature 509:310-317

44. Idzko M, Ferrari D, Riegel AK, Eltzschig HK (2014) Extracellular nucleotide and nucleoside signaling in vascular and blood disease. Blood 124:1029-1037

45. Hart ML, Gorzolla IC, Schittenhelm J, Robson SC, Eltzschig HK (2010) SP1-dependent induction of CD39 facilitates hepatic ischemic preconditioning. J Immunol 184:4017-4024

46. Hart ML, Henn M, Kohler D et al (2008) Role of extracellular nucleotide phosphohydrolysis in intestinal ischemia-reperfusion injury. FASEB J 22:2784-2797

47. Hart ML, Much C, Gorzolla IC et al (2008) Extracellular adenosine production by ecto-5'-nucleotidase protects during murine hepatic ischemic preconditioning. Gastroenterology 135:17391750

48. Eltzschig HK, Carmeliet P (2011) Hypoxia and inflammation. N Engl J Med 364:656-665

49. Eltzschig HK, Sitkovsky MV, Robson SC (2012) Purinergic signaling during inflammation. N Engl J Med 367:2322-2333

50. Chouker A, Ohta A, Martignoni A et al (2012) In vivo hypoxic preconditioning protects from warm liver ischemia-reperfusion injury through the adenosine $\mathrm{A} 2 \mathrm{~B}$ receptor. Transplantation 94 : 894-902

51. Eltzschig HK, Ibla JC, Furuta GT et al (2003) Coordinated adenine nucleotide phosphohydrolysis and nucleoside signaling in posthypoxic endothelium: role of ectonucleotidases and adenosine A2B receptors. J Exp Med 198:783-796

52. Kong T, Westerman KA, Faigle M, Eltzschig HK, Colgan SP (2006) HIF-dependent induction of adenosine A2B receptor in hypoxia. FASEB J 20:2242-2250

53. Lappas CM, Day YJ, Marshall MA, Engelhard VH, Linden J (2006) Adenosine A2A receptor activation reduces hepatic ischemia reperfusion injury by inhibiting CD1d-dependent NKT cell activation. J Exp Med 203:2639-2648

54. Ahmad A, Ahmad S, Glover L et al (2009) Adenosine A2A receptor is a unique angiogenic target of HIF-2alpha in pulmonary endothelial cells. Proc Natl Acad Sci U S A 106:10684-10689

55. Eltzschig HK, Abdulla P, Hoffman E et al (2005) HIF-1dependent repression of equilibrative nucleoside transporter (ENT) in hypoxia. J Exp Med 202:1493-1505

56. Morote-Garcia JC, Kohler D, Roth JM et al (2013) Repression of the equilibrative nucleoside transporters dampens inflammatory lung injury. Am J Respir Cell Mol Biol 49:296-305

57. Guo JY, Yang T, Sun XG et al (2011) Ischemic postconditioning attenuates liver warm ischemia-reperfusion injury through AkteNOS-NO-HIF pathway. J Biomed Sci 18:79

58. Plock J, Frese S, Keogh A et al (2007) Activation of non-ischemic, hypoxia-inducible signalling pathways up-regulate cytoprotective genes in the murine liver. J Hepatol 47:538-545

59. Amador A, Grande L, Marti J et al (2007) Ischemic preconditioning in deceased donor liver transplantation: a prospective randomized clinical trial. Am J Transplant 7:2180-2189

60. Eltzschig HK, Bratton DL, Colgan SP (2014) Targeting hypoxia signalling for the treatment of ischaemic and inflammatory diseases. Nat Rev Drug Discov 13:852-869
61. Bedogni G, Miglioli L, Masutti F et al (2005) Prevalence of and risk factors for nonalcoholic fatty liver disease: the Dionysos nutrition and liver study. Hepatology 42:44-52

62. Nonomura A, Mizukami Y, Unoura M et al (1992) Clinicopathologic study of alcohol-like liver disease in nonalcoholics; non-alcoholic steatohepatitis and fibrosis. Gastroenterol Jpn 27:521-528

63. Omagari K, Kadokawa Y, Masuda J et al (2002) Fatty liver in nonalcoholic non-overweight Japanese adults: incidence and clinical characteristics. J Gastroenterol Hepatol 17:1098-1105

64. McCullough AJ (2011) Epidemiology of the metabolic syndrome in the USA. J Dig Dis 12:333-340

65. Torres DM, Harrison SA (2008) Diagnosis and therapy of nonalcoholic steatohepatitis. Gastroenterology 134:1682-1698

66. Szczepaniak LS, Nurenberg P, Leonard D et al (2005) Magnetic resonance spectroscopy to measure hepatic triglyceride content: prevalence of hepatic steatosis in the general population. Am J Physiol Endocrinol Metab 288:E462-E468

67. Argo CK, Caldwell SH (2009) Epidemiology and natural history of non-alcoholic steatohepatitis. Clin Liver Dis 13:511-531

68. Hui JM, Kench JG, Chitturi S et al (2003) Long-term outcomes of cirrhosis in nonalcoholic steatohepatitis compared with hepatitis C. Hepatology 38:420-427

69. Adams LA, Lymp JF, St SJ et al (2005) The natural history of nonalcoholic fatty liver disease: a population-based cohort study. Gastroenterology 129:113-121

70. Nasrin N, Wu X, Fortier E et al (2010) SIRT4 regulates fatty acid oxidation and mitochondrial gene expression in liver and muscle cells. J Biol Chem 285:31995-32002

71. Kondo K, Sugioka T, Tsukada K et al (2010) Fenofibrate, a peroxisome proliferator-activated receptor alpha agonist, improves hepatic microcirculatory patency and oxygen availability in a high-fat-diet-induced fatty liver in mice. Adv Exp Med Biol 662: $77-82$

72. Henly DC, Berry MN (1993) Effect of palmitate concentration on the relative contributions of the beta-oxidation pathway and citric acid cycle to total $\mathrm{O} 2$ consumption of isolated rat hepatocytes. Biochim Biophys Acta 1175:269-276

73. Piguet AC, Stroka D, Zimmermann A, Dufour JF (2010) Hypoxia aggravates non-alcoholic steatohepatitis in mice lacking hepatocellular PTEN. Clin Sci (Lond) 118:401-410

74. Gordon GB, Barcza MA, Bush ME (1977) Lipid accumulation of hypoxic tissue culture cells. Am J Pathol 88:663-678

75. Parathath S, Mick SL, Feig JE et al (2011) Hypoxia is present in murine atherosclerotic plaques and has multiple adverse effects on macrophage lipid metabolism. Circ Res 109:1141-1152

76. Furuta E, Pai SK, Zhan R et al (2008) Fatty acid synthase gene is up-regulated by hypoxia via activation of Akt and sterol regulatory element binding protein-1. Cancer Res 68:1003-1011

77. Minamishima YA, Moslehi J, Padera RF et al (2009) A feedback loop involving the Phd3 prolyl hydroxylase tunes the mammalian hypoxic response in vivo. Mol Cell Biol 29:5729-5741

78. Rankin EB, Rha J, Selak MA et al (2009) Hypoxia-inducible factor 2 regulates hepatic lipid metabolism. Mol Cell Biol 29: $4527-4538$

79. Kim WY, Safran M, Buckley MR et al (2006) Failure to prolyl hydroxylate hypoxia-inducible factor alpha phenocopies VHL inactivation in vivo. EMBO J 25:4650-4662

80. Suzuki T, Shinjo S, Arai T, Kanai M, Goda N (2014) Hypoxia and fatty liver. World J Gastroenterol 20:15087-15097

81. Mandayam S, Jamal MM, Morgan TR (2004) Epidemiology of alcoholic liver disease. Semin Liver Dis 24:217-232

82. O'Shea RS, Dasarathy S, McCullough AJ (2010) Alcoholic liver disease. Hepatology 51:307-328

83. Gao B, Bataller R (2011) Alcoholic liver disease: pathogenesis and new therapeutic targets. Gastroenterology 141:1572-1585 
84. Raynard B, Balian A, Fallik D et al (2002) Risk factors of fibrosis in alcohol-induced liver disease. Hepatology 35:635-638

85. Naveau S, Giraud V, Borotto E et al (1997) Excess weight risk factor for alcoholic liver disease. Hepatology 25:108-111

86. Siu L, Foont J, Wands JR (2009) Hepatitis C virus and alcohol. Semin Liver Dis 29:188-199

87. Yuki T, Thurman RG (1980) The swift increase in alcohol metabolism. Time course for the increase in hepatic oxygen uptake and the involvement of glycolysis. Biochem J 186:119-126

88. Israel Y, Videla L, Macdonald A, Bernstein J (1973) Metabolic alterations produced in the liver by chronic ethanol administration. Comparison between the effects produced by ethanol and by thyroid hormones. Biochem J 134:523-529

89. French SW (2004) The role of hypoxia in the pathogenesis of alcoholic liver disease. Hepatol Res 29:69-74

90. Arteel GE, Raleigh JA, Bradford BU, Thurman RG (1996) Acute alcohol produces hypoxia directly in rat liver tissue in vivo: role of Kupffer cells. Am J Physiol 271:G494-G500

91. Arteel GE, Iimuro Y, Yin M, Raleigh JA, Thurman RG (1997) Chronic enteral ethanol treatment causes hypoxia in rat liver tissue in vivo. Hepatology 25:920-926

92. Nishiyama Y, Goda N, Kanai M et al (2012) HIF-1alpha induction suppresses excessive lipid accumulation in alcoholic fatty liver in mice. J Hepatol 56:441-447

93. Nath B, Levin I, Csak T et al (2011) Hepatocyte-specific hypoxiainducible factor-1 alpha is a determinant of lipid accumulation and liver injury in alcohol-induced steatosis in mice. Hepatology 53: 1526-1537

94. Li L, Chen SH, Zhang Y et al (2006) Is the hypoxia-inducible factor-1 alpha mRNA expression activated by ethanol-induced injury, the mechanism underlying alcoholic liver disease? Hepatobiliary Pancreat Dis Int 5:560-563

95. Alcolado R, Arthur MJ, Iredale JP (1997) Pathogenesis of liver fibrosis. Clin Sci (Lond) 92:103-112

96. Stewart SF, Day CP (2003) The management of alcoholic liver disease. JHepatol 38(Suppl 1):S2-13

97. Coulon S, Heindryckx F, Geerts A et al (2011) Angiogenesis in chronic liver disease and its complications. Liver Int 31:146-162

98. Cabibbo G, Maida M, Genco C, Antonucci M, Camma C (2012) Causes of and prevention strategies for hepatocellular carcinoma. Semin Oncol 39:374-383

99. Hashimoto E, Yatsuji S, Tobari M et al (2009) Hepatocellular carcinoma in patients with nonalcoholic steatohepatitis. J Gastroenterol 44(Suppl 19):89-95

100. Vanhaecke T, Foriers A, Geerts A et al (2001) Pyruvate-induced long-term maintenance of glutathione s-transferase in rat hepatocyte cultures. Altern Lab Anim 29:335-346

101. Onori P, Morini S, Franchitto A et al (2000) Hepatic microvascular features in experimental cirrhosis: a structural and morphometrical study in CCl4-treated rats. J Hepatol 33:555-563

102. Moon JO, Welch TP, Gonzalez FJ, Copple BL (2009) Reduced liver fibrosis in hypoxia-inducible factor-1alpha-deficient mice. Am.J Physiol Gastrointest. Liver Physiol 296:G582-G592

103. Novo E, Cannito S, Zamara E et al (2007) Proangiogenic cytokines as hypoxia-dependent factors stimulating migration of human hepatic stellate cells. Am J Pathol 170:1942-1953

104. Roychowdhury S, Chiang DJ, McMullen MR, Nagy LE (2014) Moderate, chronic ethanol feeding exacerbates carbontetrachloride-induced hepatic fibrosis via hepatocyte-specific hypoxia inducible factor 1alpha. Pharmacol Res Perspect 2:e00061

105. Copple BL, Kaska S, Wentling C (2012) Hypoxia-inducible factor activation in myeloid cells contributes to the development of liver fibrosis in cholestatic mice. J Pharmacol Exp Ther 341:307-316

106. Chan ES, Montesinos MC, Fernandez P et al (2006) Adenosine $\mathrm{A}(2 \mathrm{~A})$ receptors play a role in the pathogenesis of hepatic cirrhosis. Br J Pharmacol 148:1144-1155
107. Chiang DJ, Roychowdhury S, Bush K et al (2013) Adenosine 2A receptor antagonist prevented and reversed liver fibrosis in a mouse model of ethanol-exacerbated liver fibrosis. PLoS ONE 8:e69114

108. Mustafa SJ, Nadeem A, Fan M et al (2007) Effect of a specific and selective $\mathrm{A}(2 \mathrm{~B})$ adenosine receptor antagonist on adenosine agonist AMP and allergen-induced airway responsiveness and cellular influx in a mouse model of asthma. J Pharmacol Exp Ther 320: 1246-1251

109. Ceradini DJ, Gurtner GC (2005) Homing to hypoxia: HIF-1 as a mediator of progenitor cell recruitment to injured tissue. Trends Cardiovasc Med 15:57-63

110. Higgins DF, Kimura K, Bernhardt WM et al (2007) Hypoxia promotes fibrogenesis in vivo via HIF-1 stimulation of epithelial-tomesenchymal transition. J Clin Invest 117:3810-3820

111. Sun S, Ning X, Zhang Y et al (2009) Hypoxia-inducible factor1alpha induces Twist expression in tubular epithelial cells subjected to hypoxia, leading to epithelial-to-mesenchymal transition. Kidney Int 75:1278-1287

112. Wilson GK, Tennant DA, McKeating JA (2014) Hypoxia inducible factors in liver disease and hepatocellular carcinoma: current understanding and future directions. J Hepatol 61:1397-1406

113. El-Serag HB (2012) Epidemiology of viral hepatitis and hepatocellular carcinoma. Gastroenterology 142:1264-1273

114. Arbuthnot P, Capovilla A, Kew M (2000) Putative role of hepatitis $\mathrm{B}$ virus $\mathrm{X}$ protein in hepatocarcinogenesis: effects on apoptosis, DNA repair, mitogen-activated protein kinase and JAK/STAT pathways. J Gastroenterol Hepatol 15:357-368

115. Ripoli M, D'Aprile A, Quarato G et al (2010) Hepatitis C viruslinked mitochondrial dysfunction promotes hypoxia-inducible factor 1 alpha-mediated glycolytic adaptation. J Virol 84:647-660

116. Liu Y, Sui J, Zhai L et al (2014) Genetic polymorphisms in hypoxia-inducible factor-1a gene and its association with HBVrelated hepatocellular carcinoma in a Chinese population. Med Oncol 31:200

117. Moon EJ, Jeong CH, Jeong JW et al (2004) Hepatitis B virus X protein induces angiogenesis by stabilizing hypoxia-inducible factor-1alpha. FASEB J 18:382-384

118. Yoo YG, Cho S, Park S, Lee MO (2004) The carboxy-terminus of the hepatitis B virus X protein is necessary and sufficient for the activation of hypoxia-inducible factor-1alpha. FEBS Lett 577: $121-126$

119. Yoo YG, Na TY, Seo HW et al (2008) Hepatitis B virus X protein induces the expression of MTA1 and HDAC1, which enhances hypoxia signaling in hepatocellular carcinoma cells. Oncogene 27: 3405-3413

120. Yoo YG, Oh SH, Park ES et al (2003) Hepatitis B virus X protein enhances transcriptional activity of hypoxia-inducible factor-1alpha through activation of mitogen-activated protein kinase pathway. J Biol Chem 278:39076-39084

121. Vassilaki N, Kalliampakou KI, Kotta-Loizou I et al (2013) Low oxygen tension enhances hepatitis C virus replication. J Virol 87: 2935-2948

122. Mee CJ, Harris HJ, Farquhar MJ et al (2009) Polarization restricts hepatitis C virus entry into HepG2 hepatoma cells. J Virol 83: 6211-6221

123. Mee CJ, Farquhar MJ, Harris HJ et al (2010) Hepatitis C virus infection reduces hepatocellular polarity in a vascular endothelial growth factor-dependent manner. Gastroenterology 138:1134 1142

124. Burnstock G, Boeynaems JM (2014) Purinergic signalling and immune cells. Purinergic Signal 10:529-564

125. Sitkovsky MV, Hatfield S, Abbott R et al (2014) Hostile, hypoxiaA2-adenosinergic tumor biology as the next barrier to overcome for tumor immunologists. Cancer Immunol Res 2:598-605 
126. Jemal A, Bray F, Center MM et al (2011) Global cancer statistics. CA Cancer J Clin 61:69-90

127. El-Serag HB, Rudolph KL (2007) Hepatocellular carcinoma: epidemiology and molecular carcinogenesis. Gastroenterology 132: 2557-2576

128. Parkin DM (2001) Global cancer statistics in the year 2000. Lancet Oncol 2:533-543

129. Gomaa AI, Khan SA, Toledano MB, Waked I, Taylor-Robinson SD (2008) Hepatocellular carcinoma: epidemiology, risk factors and pathogenesis. World J Gastroenterol 14:4300-4308

130. Aravalli RN, Steer CJ, Cressman EN (2008) Molecular mechanisms of hepatocellular carcinoma. Hepatology 48:2047-2063

131. Cabrera R, Nelson DR (2010) Review article: the management of hepatocellular carcinoma. Aliment Pharmacol Ther 31:461-476

132. Liu Y, Liu Y, Yan X et al (2014) HIFs enhance the migratory and neoplastic capacities of hepatocellular carcinoma cells by promoting EMT. Tumour Biol 35:8103-8114

133. Bangoura G, Liu ZS, Qian Q et al (2007) Prognostic significance of HIF-2alpha/EPAS1 expression in hepatocellular carcinoma. World J Gastroenterol 13:3176-3182

134. Simon F, Bockhorn M, Praha C et al (2010) Deregulation of HIF1alpha and hypoxia-regulated pathways in hepatocellular carcinoma and corresponding non-malignant liver tissue - influence of a modulated host stroma on the prognosis of HCC. Langenbecks Arch Surg 395:395-405

135. Xiang ZL, Zeng ZC, Fan J et al (2012) The expression of HIF1alpha in primary hepatocellular carcinoma and its correlation with radiotherapy response and clinical outcome. Mol Biol Rep 39:2021-2029

136. Yang SL, Liu LP, Jiang JX et al (2014) The correlation of expression levels of HIF-1alpha and HIF-2alpha in hepatocellular carcinoma with capsular invasion, portal vein tumor thrombi and patients' clinical outcome. Jpn J Clin Oncol 44:159-167

137. Zheng SS, Chen XH, Yin X, Zhang BH (2013) Prognostic significance of HIF-1alpha expression in hepatocellular carcinoma: a meta-analysis. PLoS One 8:e65753

138. Guo X, Li D, Chen Y et al (2015) SNP rs2057482 in HIF1A gene predicts clinical outcome of aggressive hepatocellular carcinoma patients after surgery. Sci Rep 5:11846

139. Hsiao PC, Chen MK, Su SC et al (2010) Hypoxia inducible factor1alpha gene polymorphism G1790A and its interaction with tobacco and alcohol consumptions increase susceptibility to hepatocellular carcinoma. J Surg Oncol 102:163-169

140. Wu XZ, Xie GR, Chen D (2007) Hypoxia and hepatocellular carcinoma: the therapeutic target for hepatocellular carcinoma. J Gastroenterol Hepatol 22:1178-1182

141. Xie H, Song J, Liu K et al (2008) The expression of hypoxiainducible factor-1alpha in hepatitis B virus-related hepatocellular carcinoma: correlation with patients' prognosis and hepatitis B virus X protein. Dig Dis Sci 53:3225-3233

142. Ke Q, Costa M (2006) Hypoxia-inducible factor-1 (HIF-1). Mol Pharmacol 70:1469-1480

143. Luo D, Wang Z, Wu J, Jiang C, Wu J (2014) The role of hypoxia inducible factor-1 in hepatocellular carcinoma. Biomed Res Int 2014:409272

144. Semenza GL (2003) Targeting HIF-1 for cancer therapy. Nat Rev Cancer 3:721-732

145. Xia L, Mo P, Huang W et al (2012) The TNF-alpha/ROS/HIF-1induced upregulation of FoxMI expression promotes HCC proliferation and resistance to apoptosis. Carcinogenesis 33:2250-2259

146. Putzer BM (2007) E2F1 death pathways as targets for cancer therapy. J Cell Mol Med 11:239-251

147. Sun HX, Xu Y, Yang XR et al (2013) Hypoxia inducible factor 2 alpha inhibits hepatocellular carcinoma growth through the transcription factor dimerization partner 3/ E2F transcription factor 1dependent apoptotic pathway. Hepatology 57:1088-1097
148. Carmeliet P, Dor Y, Herbert JM et al (1998) Role of HIF-1alpha in hypoxia-mediated apoptosis, cell proliferation and tumour angiogenesis. Nature 394:485-490

149. Kim JW, Dang CV (2006) Cancer's molecular sweet tooth and the Warburg effect. Cancer Res 66:8927-8930

150. Semenza GL, Roth PH, Fang HM, Wang GL (1994) Transcriptional regulation of genes encoding glycolytic enzymes by hypoxia-inducible factor 1 . J Biol Chem 269:23757-23763

151. Semenza GL (2007) HIF-1 mediates the Warburg effect in clear cell renal carcinoma. J Bioenerg Biomembr 39:231-234

152. Seagroves TN, Ryan HE, Lu H et al (2001) Transcription factor HIF-1 is a necessary mediator of the pasteur effect in mammalian cells. Mol Cell Biol 21:3436-3444

153. Josko J, Gwozdz B, Jedrzejowska-Szypulka H, Hendryk S (2000) Vascular endothelial growth factor (VEGF) and its effect on angiogenesis. Med Sci Monit 6:1047-1052

154. Kim JW (2010) Hypoxia-inducible factor 1, hepatocellular carcinoma and angiogenesis. Korean J Hepatol 16:278-279

155. Rey S, Semenza GL (2010) Hypoxia-inducible factor-1dependent mechanisms of vascularization and vascular remodelling. Cardiovasc Res 86:236-242

156. Imai $\mathrm{T}$, Horiuchi $\mathrm{A}$, Wang $\mathrm{C}$ et al (2003) Hypoxia attenuates the expression of E-cadherin via up-regulation of SNAIL in ovarian carcinoma cells. Am J Pathol 163:1437-1447

157. Krishnamachary B, Zagzag D, Nagasawa H et al (2006) Hypoxiainducible factor-1-dependent repression of E-cadherin in von Hippel-Lindau tumor suppressor-null renal cell carcinoma mediated by TCF3, ZFHX1A, and ZFHX1B. Cancer Res 66:27252731

158. Yang MH, Wu MZ, Chiou SH et al (2008) Direct regulation of TWIST by HIF-1alpha promotes metastasis. Nat Cell Biol 10: 295-305

159. Zhang L, Huang G, Li X et al (2013) Hypoxia induces epithelialmesenchymal transition via activation of SNAI1 by hypoxiainducible factor -1alpha in hepatocellular carcinoma. BMC Cancer 13:108

160. Yang MH, Chen CL, Chau GY et al (2009) Comprehensive analysis of the independent effect of twist and snail in promoting metastasis of hepatocellular carcinoma. Hepatology 50:14641474

161. Okazaki I, Inagaki Y (2012) Novel strategies for hepatocellular carcinoma based on MMPs science. Anticancer Agents Med Chem 12:753-763

162. Sato H, Kida Y, Mai M et al (1992) Expression of genes encoding type IV collagen-degrading metalloproteinases and tissue inhibitors of metalloproteinases in various human tumor cells. Oncogene 7:77-83

163. Ding JY, Kreipke CW, Schafer P et al (2009) Synapse loss regulated by matrix metalloproteinases in traumatic brain injury is associated with hypoxia inducible factor-1alpha expression. Brain Res 1268:125-134

164. Erdozain OJ, Pegrum S, Winrow VR, Horrocks M, Stevens CR (2011) Hypoxia in abdominal aortic aneurysm supports a role for HIF-1alpha and Ets-1 as drivers of matrix metalloproteinase upregulation in human aortic smooth muscle cells. J Vasc Res 48: $163-170$

165. Fujiwara S, Nakagawa K, Harada H et al (2007) Silencing hypoxia-inducible factor-1alpha inhibits cell migration and invasion under hypoxic environment in malignant gliomas. Int J Oncol 30:793-802

166. Knowles HJ, Raval RR, Harris AL, Ratcliffe PJ (2003) Effect of ascorbate on the activity of hypoxia-inducible factor in cancer cells. Cancer Res 63:1764-1768

167. Kung AL, Wang S, Klco JM, Kaelin WG, Livingston DM (2000) Suppression of tumor growth through disruption of hypoxiainducible transcription. Nat Med 6:1335-1340 
168. Lin D, Wu J (2015) Hypoxia inducible factor in hepatocellular carcinoma: a therapeutic target. World J Gastroenterol 21: 12171-12178

169. Rapisarda A, Uranchimeg B, Sordet O et al (2004) Topoisomerase I-mediated inhibition of hypoxia-inducible factor 1: mechanism and therapeutic implications. Cancer Res 64:1475-1482

170. Abe Y, Uchinami H, Kudoh K et al (2012) Liver epithelial cells proliferate under hypoxia and protect the liver from ischemic injury via expression of HIF-1 alpha target genes. Surgery 152:869-878

171. Maeno H, Ono T, Dhar DK et al (2005) Expression of hypoxia inducible factor-1alpha during liver regeneration induced by partial hepatectomy in rats. Liver Int 25:1002-1009

172. Tajima T, Goda N, Fujiki N et al (2009) HIF-1alpha is necessary to support gluconeogenesis during liver regeneration. Biochem Biophys Res Commun 387:789-794

173. Liu F, Dong X, Lv H et al (2015) Targeting hypoxia-inducible factor-2alpha enhances sorafenib antitumor activity via beta-catenin/C-Myc-dependent pathways in hepatocellular carcinoma. Oncol Lett 10:778-784

174. Meijer TW, Kaanders JH, Span PN, Bussink J (2012) Targeting hypoxia, HIF-1, and tumor glucose metabolism to improve radiotherapy efficacy. Clin Cancer Res 18:5585-5594

175. Schwartz DL, Bankson J, Bidaut L et al (2011) HIF-1-dependent stromal adaptation to ischemia mediates in vivo tumor radiation resistance. Mol Cancer Res 9:259-270

176. Wu L, Fu Z, Zhou S et al (2014) HIF-1alpha and HIF-2alpha: siblings in promoting angiogenesis of residual hepatocellular carcinoma after high-intensity focused ultrasound ablation. PLoS One 9:e88913

177. Yamada S, Utsunomiya T, Morine Y et al (2014) Expressions of hypoxia-inducible factor-1 and epithelial cell adhesion molecule are linked with aggressive local recurrence of hepatocellular carcinoma after radiofrequency ablation therapy. Ann Surg Oncol 21(Suppl 3):S436-S442

178. Zhao D, Zhai B, He C et al (2014) Upregulation of HIF-2alpha induced by sorafenib contributes to the resistance by activating the TGF-alpha/EGFR pathway in hepatocellular carcinoma cells. Cell Signal 26:1030-1039

179. Liang Y, Zheng T, Song R et al (2013) Hypoxia-mediated sorafenib resistance can be overcome by EF24 through Von HippelLindau tumor suppressor-dependent HIF-1alpha inhibition in hepatocellular carcinoma. Hepatology 57:1847-1857

180. Liu F, Wang P, Jiang X et al (2008) Antisense hypoxia-inducible factor 1alpha gene therapy enhances the therapeutic efficacy of doxorubicin to combat hepatocellular carcinoma. Cancer Sci 99: 2055-2061

181. Eckle T, Brodsky K, Bonney M et al (2013) HIF1A reduces acute lung injury by optimizing carbohydrate metabolism in the alveolar epithelium. PLoS Biol 11:e1001665

182. Hartmann H, Eltzschig HK, Wurz H et al (2008) Hypoxiaindependent activation of HIF-1 by enterobacteriaceae and their siderophores. Gastroenterology 134:756-767 